\title{
Jim 0’Driscoll* \\ Dances with footings: a Goffmanian perspective on the Soto case
}

https://doi.org/10.1515/pr-2017-0038

Abstract: This paper attempts to explain the trajectory and unusual outcome of this courtroom encounter by applying Erving Goffman's approach to interaction. It employs his notions of frame and footing, plus those of face, ritual deference and demeanour when they are useful. This perspective shows that, as well as the socially constituted power asymmetry, the participants create an interactive asymmetry in which the accused, Penelope Soto, although a canonically ratified participant, is sometimes effectively 'de-ratified'. However, as the encounter progresses, Soto and the judge shift their footings back and forth such that into the court-hearing frame, another frame, that of the social encounter, is insinuated. This clash of frames is shown to be a major cause of the trajectory taken by the encounter. The Goffmanian perspective also points up the effect of the use of a video link for this encounter. This application of Goffman's framework functions as a test of some of his concepts and the paper concludes with some comments and suggested elaborations.

Keywords: Goffman, frame, footing, participation framework, face, demeanour, ritual deference

\section{Introduction: the problems}

Along with most others in this volume, the main impetus for this paper is the desire to understand how a routine procedure in a mundane legal case ended so unexpectedly and seriously; the outcome was not only highly undesirable for Soto (the defendant) but also (at the least) problematic for the legal authorities. How did it come about? A step-by-step description of effects and the triggers for them can be rendered thus:

*Corresponding author: Jim O'Driscoll, Linguistics Department, School of Music Humanities and Media, University of Huddersfield, Huddersfield, United Kingdom,

E-mail: J.O’Driscoll@hud.ac.uk 
The judge sentenced Soto to 30 days in jail because she said "fuck you" at him and gave him the finger

because he doubled her bail from $\$ 5,000$ dollars to $\$ 10,000$ dollars because she said "adios" to him

because he said and waved "bye-bye" to her

because ?

There is a question to be answered at the end of this backwards chain because it is clear (see section 2 and end of section 5 below) that "bye-bye" with a farewell gesture is not the usual way this judge concludes his dealings with inmates in court hearings. To attempt to find out why he did this, therefore, we need to go further back and explore the interaction up to this point. In doing so, we can also approach more nuanced understandings of the other links in the chain. The box above presents only a mechanistic, surface set of explanations. In fact, not one of those actions is determined by the preceding one. Even the final outcome, though perhaps not surprising, appears to be problematic (see the discussion in the court after Soto has finally departed). Going back one link, it is not at all self-evident that the judge doubling the bail should lead to Soto's outburst - she could have guessed that dire consequences would follow. It is equally puzzling as to why the judge reacted to that one single word from Soto by doubling the bail he had just set. The only obvious provocation is its unorthodoxy in a context where one would expect the subordinate person to choose 'safe' forms. So this action needs explaining too.

The directional thrust of this article, then, is to approach a plausible set of explanations for the trajectory taken by the meeting between the judge and Soto. This aim is pursued chiefly through the lens of Erving Goffman's work. In the process of this exercise, therefore, a test is conducted of the applicability of some aspects of his architecture of interaction and some elaborations can be suggested.

\section{Before the beginning}

Before the judge starts dealing with Soto, we see her standing some 5 metres directly behind another inmate, in the apparently designated 'up-next' position (the white rectangle on the floor of the jailhouse - see video), waiting for this other inmate's dealings with the judge to conclude. The judge announces the bail amount, issues a verbal order to the inmate to 'stay away from' a certain person and then puts aside a document he has been working with, all without once directing his gaze to the inmate. The inmate appears momentarily be- 
mused but then realizes that her case is concluded and that she can/should now leave the position designated for dealings with the judge. Accordingly, she turns to her right and shuffles silently off camera.

At this point, Soto steps forward towards the position just vacated but then, after turning her gaze briefly and slightly to the left, halts before she gets there, presumably on the instruction of an authority figure in the jailhouse. She then waits in this in-between position for a full 15 seconds while the judge completes the paperwork from the previous case. Only when the judge calls out her name does she step fully forward into the designated position.

\section{Goffman's conceptual apparatus}

A Goffmanian approach starts from his very simple but inclusive understanding of interaction as conscious co-presence. That is, whenever two or more people are within sight and/or sound of each other, and know that they are, there is interaction. The subset of these circumstances more commonly meant by 'interaction' is what Goffman calls focused interaction, which occurs when people extend to each other the status of co-participants and "jointly ratify one another as authorized co-sustainers of a single... focus of visual and cognitive attention" (Goffman 1964: 135). Each identifiable spate of focused interaction with some sort of recognizable beginning and end is called an encounter. ${ }^{1}$

The above-described hiatus in the initiation of the Soto-judge encounter illustrates unfocused interaction. Soto is aware of the judge's presence and that of others, and also aware that those others are aware of her presence. This mutual awareness has effects on her behaviour. A significant feature of all interaction is that this awareness of others' awareness of us puts constraints on what we do (Goffman 1963b: 24-88). Only when the judge calls out her name, which appears to be the standard means by which these encounters are opened (see end of video), does he recognize Soto as a co-participant.

The hiatus serves to illustrate two further aspects of the Goffmanian perspective. One is that interaction, being mere co-presence, does not itself entail talk. This means that if we are to understand a spate of interaction fully, we need to examine not only what is said but also what else is done. Thus, although we may speak of utterances, turns at talk, phrases, clauses or the like, the basic unit of analysis is the move (Goffman 1981: 23-29), the former being merely examples or constituents of the latter.

1 For a global summary account of Goffman's working framework for the study of interaction, see O'Driscoll (2009: 85-89). For a reasonably concise account of the aspects of this approach summarized in this paragraph, see Goffman (1967: 137-148). 
The other point comes from the observation that this silence at the encounter's 'false-start' is just one example of several hiatuses in talk which take place during it. This encounter, therefore, cannot be described as a conversation. Talk is necessary for it but not for its own sake. Rather, we are dealing here with what Goffman (1981: 143) calls “a state of inquiry”. This means that in order to enquire into the meaning and effect of any move, we must in the first instance consider its relation to the assumed purpose of the encounter (Goffman 1964; 1981: 141-143).

The matter of purpose brings us to the concepts of frame (Goffman 1974) and footing (Goffman 1981). The former term has been used for a wide variety of cognitive constructs (see Tannen 1993 for a review) which overlap with the notions of 'schema' and 'script', probably the most well-known of which is Schank and Abelson's (1977) restaurant script. But for Goffman, focusing primarily on interaction rather than mental constructs, it involves "principles of organization which govern events ... and our subjective involvement in them" (Goffman 1974: 10). As such, it covers most of the same ground as Levinson's (1979) notion of activity type and is one way of addressing the question: what sort of thing is going on here? Goffman himself also explores this matter elsewhere as "definition of the situation" (Goffman 1959) and "social occasion" (Goffman 1963b). Whichever term is used, this concept concerns expectations about the setting for activity, its goals, the focus of attention and topic(s) of any talk and, crucially, participants' behaviour. For investigating this last aspect, Levinson starts with socially constituted expectations and thus emphasizes a range of "allowable contributions" (Levinson 1979: 368). Goffman, on the other hand, starts from the subjective nature of expectations and thus focuses on the roles of individual participants and how they present themselves - and how these roles and self-presentations are negotiated. Indeed, he offers examples (Goffman 1963b: 20) of interactants having different assumptions about what exactly is going on and therefore what sort of behaviour is appropriate. This potential for divergent assumptions of frame turns out to be relevant in the Soto case (see below).

The more subjective focus leads to his allied notion of footing, which affords a close-up view of the dynamics of interaction as it takes place. Indeed, Goffman defines the notion only in dynamic terms: "A change in footing implies a change in the alignment we take up to ourselves and others present as expressed in the way we manage the production or reception of an utterance." (Goffman 1981: 128) This focus on change implies something to change from, some aspects of which are brought along to an encounter before it begins, a fact apparently recognized by Goffman when offering examples of changes in footing which involve "an alteration in the social capacities in which the persons present claim to be active" (1981: 126). Thus this concept, while focusing 
attention on the moment-by-moment manoeuvrings of interaction, takes account of situationally and socially ordained roles. Scholars have long recognized these two aspects of role and the need to distinguish them in terms of scale (e.g., Irvine 1996): the one intra-situational, referring to the relation between a participant and an utterance; the other extra-situationally assigned (initially at least) referring to the relation between a participant and the encounter. Some (e.g., Thomas 1986; Sarangi and Slembrouck 1996; Halvorsen and Sarangi 2015) have conceptualized them as a distinction between 'discourse roles' and 'activity (or 'social') roles' respectively. They have also recognized that the one can affect the other, so that the roles which participants actually play during interaction are subject to change as a result of what they and other participants do and so "a change in our footing is another way of talking about a change in our frame for events" (Goffman 1981: 128 - see also Goodwin and Duranti 1992: 5 on the dynamic reshaping of context). For the purposes of this paper, we may say that footing describes a participant's interpersonal and social stance at a particular moment in an encounter, while frame involves a prototype of all participants' stances for an encounter as a whole. Crucially for this analysis, it has been convincingly shown (e.g., Sarangi and Slembrouck 1996: 66-71) that these footings are interpreted and assessed in the light of this prototype.

The analysis in this paper also makes use of the concepts of face, demeanour and ritual deference and. The first of these is defined (Goffman 1967: 5) as the situationally contingent, other-bestowed image of self. In the context of this paper, it can be thought of as the self-image which a participant finds themselves projecting as a result of their understanding of other participants' understandings of their footing. ${ }^{2}$ Demeanour is that aspect of self-presentation "typically conveyed through deportment, dress and bearing, which serves to express to those in [a person's] immediate presence that he is a person of certain desirable or undesirable qualities" (Goffman 1967: 77).

The phrase 'ritual deference' is a conflation of Goffman's definition of ritual as "a perfunctory, conventionalized act through which an individual portrays his respect and regard for some object of ultimate value to that object of ultimate value" (1971: 88) and his use of deference as "that component of activity which functions as a symbolic means by which appreciation is regularly conveyed to a recipient of this recipient" (1967: 56 - original italics). As can be seen, these two describe more-or-less the same kind of behaviour and Goffman's ensuing elaboration in both cases emphasizes its quotidian and ubiquitous occurrence in human interaction. Indeed, by virtue of such occur-

2 For an overview of the vast amount of scholarship on face which has taken place since Goffman first introduced this concept in 1955, see O'Driscoll (2017). 
rence, and by virtue of its 'perfunctory' and/or 'symbolic' enactment, ritual deference goes mostly unnoticed by those giving and receiving it, being merely one aspect of what Watts $(1989,1992,2003)$ and many scholars since have termed politic behaviour. As such, in most kinds of encounter, the 'unmarked' kind where no special instrumental urgency, interpersonal antagonism or power asymmetry is in play, it is part of our frame for behaviour. Its frequent absence in the encounter examined here is indicative of a 'marked' encounter.

\section{The frame for this encounter}

The 'prequel' to this encounter (see section 2) is one enactment of the stark power asymmetry which obtains in this kind of encounter. Not only has its general scheduling been arranged by the authorities; the judge's behaviour demonstrates that he has the right to decide the precise moment at which it actually commences. It is also the judge who decides when it finishes and, of course, it is he and the other legal professionals taking part in the encounter who direct the topic(s) of talk. In addition to these canonical aspects of the encounter as an event, there are several physical realities which impact on the demeanour of the two main interactants and contribute to the power asymmetry.

Clothing: The judge is wearing the robes of judicial authority, while Soto is clad in the signature garb of the incarcerated. Note also that under his robes the judge is wearing clothes of his own choosing, while Soto appears to have been stripped of these means for self-presentation.

Posture: Throughout the encounter, the judge is sitting, Soto is standing. With the exception of occasions when standing indexes greater freedom of movement than that of the sitter, it is invariably the case that the sitting party is the one with greater power in an encounter. Notice that in western culture at least, a directive to sit down is typically read as an invitation, while one to stand up is typically considered an instruction.

Props: As well as the swivel chair in which he sits, the judge has many props for his body or parts of it. He sits behind a large desk on which he can rest his arms. In his hand is a pen which he can wield to make marks on the documents which lie on the desk and with which he can legitimately busy himself. Soto, on the other hand, has nothing with which her body can take shelter from exposure. She appears to stand in an empty space. ${ }^{3}$ And, as she

3 In fact, at the onset of the next encounter, the inmate appears to rest her arms on some sort of surface just visible at the bottom of the screen, but Soto never avails herself of this potential prop. 
holds nothing about her person and her coveralls have no pockets, she has no opportunity for 'side-involvements' (Goffman 1963b: 43-63). Her only available prop is her hair, which she makes extensive use of during the encounter. ${ }^{4}$ This circumstance - being rooted to the spot without props - is an unusual one for an interactant to find themselves in. That it is one which is discomfortingly unfamiliar to Soto is witnessed by the many postural adjustments which she makes during the encounter, including one when she appears to stagger slightly. And owing to the lack of props, these adjustments are foregrounded in the eyes of observers. They become so salient that they can be received as possible evidence of incapacity, as when the judge enquires whether she is under the influence of drugs. ${ }^{5}$

Orientation: To look directly at the judge and the other participants at the other end of the video link, Soto has to look straight ahead. But the judge, in order to look directly at Soto, has to turn his neck, trunk or swivel chair to his right side. This asymmetry is significant because changes in orientation have been shown to signal adjustments in frame (Kendon 1990) and in this case gaze is a contributory factor in the participation statuses of the two (see next section).

\section{Participation framework: the de-ratification of Soto}

To circumscribe that aspect of participants' footings which is to do with their purely operational role in an encounter, Goffman (1981: 129-143) offers what he calls participation framework. This distinguishes firstly between those who are ratified participants and those who are merely bystanders. These latter have no rights or obligations to take an active part in the encounter but they are aware that it is taking place and often can be sufficiently within eyeshot and/ or earshot to catch details of what the ratified participants are doing, such as what they are saying, in which case they become overhearers. They are important because ratified participants tend to take account of their presence (see Goffman 1981: 85-98), a crucial example of which can be witnessed at the end of the encounter examined here (see section 7.4 below).

4 Thanks to Tilly Flint and Helen Attwood for drawing my attention to hair as prop.

5 This condition, whereby a person's immediate circumstances cause them to behave in a conventionally unorthodox manner which is then read as evidence of their unfitness for life in society at large, is one which Goffman draws attention to in his analysis of mental patients (Goffman 1961; see also Goffman 1963a; 1967: 67). 
Among ratified participants, Goffman distinguishes not only between speaker and hearer but also deconstructs the latter into addressed and unaddressed. That is, there may be a person (or people) present who the speaker is not addressing but who nevertheless is (are) fully ratified in the sense that they are accorded the right to hear completely what is said and often the right to self-select for the next turn. The extent to which they have this latter right depends largely on the frame. Many encounters are more structured and purposeful than prototypical casual conversation and in these cases the right is often restricted and distributed unequally. The encounter examined here is an example.

As can be inferred, Goffman presents any itemizing of participants in this way as 'cross-sectional'; that is, a way to capture a frozen moment in time. Of course, in most kinds of encounter, speakers and hearers often swap roles as it progresses, and ratified participants who are unaddressed at one moment may be addressed at the next or themselves become the speaker. If we combine these dynamic considerations with the concept of frame, it seems clear that certain kinds of encounter dictate, or at least predispose towards, certain patterns of participation framework throughout their course, including particular roles, rights and obligations allocated to particular participants (hence the notion of activity role - see section 3 above). In a pub conversation, for example, one would expect frequent and rapid alternations of occupation of the speaker, addressed and unaddressed slots, with no discernible order or specialist allocations. In a job interview, on the other hand, one would expect less frequent changes and a recognizable, probably pre-arranged, order of allocations among members of the panel (and also, possibly, an 'observer' to see fair play - that is, a fully ratified participant who is confined to the unaddressed role throughout). With these considerations in mind, it should be possible to identify a characteristic participation-framework pattern for most kinds of encounter.

In the case of these pre-trial courtroom hearings, we may say that the canonical pattern is as follows:

\begin{tabular}{|c|c|c|c|c|c|}
\hline Ratified & pants & $\gg>$ & $\gg>$ & $\gg \gg$ & $\gg>$ \\
\hline Speaker & & judge & inmate & judge & inmate \\
\hline Others & addressed & inmate & judge & inmate & judge \\
\hline & unaddressed & legal staff & legal staff & legal staff & legal staff \\
\hline
\end{tabular}

That is, we can assume that the encounter will take the shape of a series of interchanges between the inmate (here, Soto) and the judge. And as Soto can speak only when spoken to, the 'ideal' participation-framework pattern for the whole encounter except its closing is a series of adjacency pairs (Schegloff 
1968; Schegloff and Sacks 1973), with the judge speaking (the first pair-part) and Soto responding relevantly (second pair-part). In addition, there are legal professionals in the courtroom who have a right - and probably a duty - to hear what is said.

However, ideal patterns tend to bend to situational exigencies. To circumscribe the interaction realities of this encounter, therefore, we need to identify a default pattern. In this case it is clear that those legal professionals have an occasional active role to play. This encounter includes several interchanges between them and the judge. In this light, we might appeal to Goffman's notion of 'subordinate communication' (Goffman 1981: 133-134). In some encounters there are moments of additional activity beyond the main focus of attention which, though they might (as here) involve a subset of ratified participants, do not divert or interfere with the 'dominating communication'. From this viewpoint, we could posit the following participation-framework pattern:

Ratified participants Speaker

Others

\section{Dominating communication}

judge Soto judge judg $\gg>$

addressed

unaddressed

Soto judge Soto judge

Subordinate communication

judge staff judge staff judge

staff staff staff staff Soto Soto Soto Soto

However, the footings adopted by the legal staff in this encounter extend well beyond assisting the judge when he asks them to. It also includes the ability to bring up new details unbidden, to interrupt the canonical dominating communication with Soto and even to self-select to take the next turn in the dominating communication - the question "Miss Soto, are you working?" is unprompted by the judge or by former turns. Given these observations, it is intuitively unsatisfactory to confine the contributions of the legal staff to the subordinate category. Instead, we can see that over the encounter as a whole, each one of the three classes of ratified participant here (the judge, Soto, the professionals) takes at least one turn at occupying each one of the three ratified slots (speaker, addressed, unaddressed), giving us a pattern as follows:

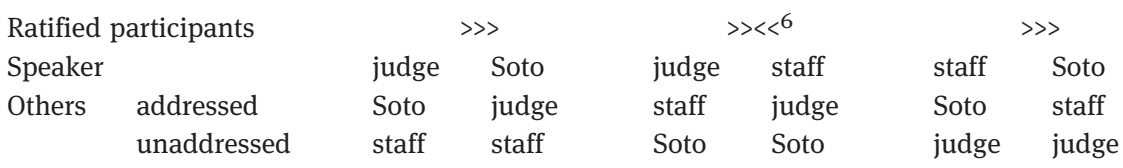

6 In this case the arrows point both ways because either party can initiate the exchange. 
But this pattern is also an unsatisfactory representation. It presents an impression of three equal parties, which would be very misleading because, unlike the other two parties, Soto has no right to self-select for the next turn. Moreover, an investigation of details of the interaction reveals a multi-faceted attenuation of the canonical framework.

First, we have seen (section 2) that before the judge calls out her name, Soto is held in a limbo between the status of bystander and that of ratified participant. After calling her forward, the judge then accords some recognition of her ratified participation status by formally greeting her ("Good morning, Miss Soto"). However, the greeting is hurried and perfunctory, with 'good' reduced to an unreleased velar stricture and by the time he has completed it, his gaze, after a brief glance in her direction, has returned to his paperwork. This glance, then, appears chiefly to assure himself that she is present rather to accord her any ritual deference. He then holds his gaze on the paperwork throughout his enunciation of what "you're being charged with ...". His subsequent admission of ignorance and query about the charge, in that he is still looking into his paperwork and the volume of his voice has reduced, is not addressed to Soto and it is answered promptly and solely by others in the courtroom. The judge is still not looking at Soto when explicitly addressing her with "you're eligible for ...”.

The apparently marginal nature of Soto's participation status indicated by these features is intensified in several ways. Structurally, there is her physical dislocation from other ratified participants, whereby she becomes a viewer of their interaction (one with not a very good view either - see section 8). Then there is the judge's physical orientation: the fact that he has to look to the side to face her implies a relatively ancillary interactional role for her. There are linguistic marginalizations too. There are third-person references by other participants to "they" (an ill-defined group but understood to include Soto) and to "she" (specifically denoting Soto) and there are also the specialist terms used by the judge and staff. While it is conceivable that Soto can follow 'pre-trial service', 'priors' and 'count', it is highly unlikely she can understand, as they are uttered, 'PTS', 'ROR' and 'division 51',7 suggesting that Soto not only has no self-selecting speaking rights, but sometimes limited hearing rights too.

All these features serve to perform a kind of de-ratification on Soto, effectively reducing her to a bystander of her own encounter. One way of dealing with such role indeterminacy is to identify additional roles which can be fitted

7 A layperson such as myself, for example, did not understand the first time around. I was able to guess PTS was short for 'pre-trial service' after some repeated listenings, but I had to google the other two. 
in to Goffman's framework. This is what Levinson (1988) does. For instance, when one canonically ratified participant is talked about as if not there, he proposes a distinction between two types of unaddressed participant, which he names audience and (indirect) target. This distinction works well in his example case, where the talked-about person is being criticized. However, it does not work so well for Soto, the salient aspect of whose marginalization is not that she is being 'got at' but rather is being distanced, even removed, from active participation. Moreover, as Irvine (1996) has argued, the number of such extra participant roles would be potentially infinite. Rather than search for a label for Soto's exact participation status at particular moments, this paper retains a Goffmanian approach to analytical categories as mere 'scaffolding' (1959: 246; 1967: 47); that is, as temporary structures used to construct an understanding of the data under examination. There is no obvious need to proliferate typological categories. Instead, we can work with the few we have and focus on how people (attempt to) manipulate their own footings and those of others by what they say and how they say it. Soto at these points is back in a limbo between ratified and unratified statuses. She has the obligations of the former status but hardly any of its rights.

The starkest indication of Soto's marginal participation status occurs at the first attempted 'closing' of the encounter. For a period of 40 seconds after the judge has last addressed her, she waits while judge and legal staff converse and the judge records on paper the decisions he announces. It finishes with 9 seconds of silence as the judge completes his paperwork. He then turns to the VL (video link) and sees with apparent mild surprise that Soto is still there at the other end of it. Soto is supposed to have gleaned that their encounter is terminated. There are plenty of cues for this intended closure: the parallelism in "count 1 will be ... count 2 will be ... and refer to division 51", the slightly raised volume of voice, the writing-down of the pronouncements. The other ratified participants, accustomed to these procedures, take these cues as constituting closure in themselves. But Soto, without their experience, does not.

Soto is what Goffman has called a 'profane' person, one to whom normally expected ritual deference is not accorded. The evidence of the closing and opening of the preceding and following encounters respectively suggests that such profanization and de-ratification are default. However, the trajectory of this particular encounter effects a gradual subversion of this default. See next section. 


\section{The dance of footings: indices of a different frame}

At the start of proceedings, Soto goes along with the profane status accorded her. She responds to the judge's calling out her name with a bare "yes", showing that she interprets it not as a greeting but as a summons and check on her identity. And when a court lawyer begins questioning her, she at first likewise falls into line. Her first three responses conform perfectly to Gricean maxims (Grice 1975): a bare 'yes' to two yes/no questions and the provision of an approximate quantity after a 'how-much-approximately' question. ${ }^{8}$

It is in response to the next question that she begins to shift her footing slightly (shown here in musical-score format: ${ }^{9}$ )

Lawyer what do you own?

OK- erp go ahead

Defendant

aha I own a lot of jewellery, alright as well as-

a car

She still gives a straight answer to the question posed here but her claim of "a lot" is unsatisfactorily vague for the court. This vagueness is accompanied by a small spate of laughter and the addition of 'alright', all evoking a more conversational style. The lawyer's “OK” in response may be the start of an attempt to halt this perceived drift to the conversational, but at the same time Soto commences to itemize other possessions, assuring him she is conforming to the instrumental frame, hence his subsequent "go-ahead".

At this point, however, the judge intervenes - and an intricate dance of footings commences. ${ }^{10}$

8 We may recognize this behaviour as the enactment of a profane status if we consider that these minimal responses would be unacceptable - and assessed as 'uncommunicative', 'unhelpful', even 'rude' - in any activity type other than one such as this, whose social constitution is such that not even the barest nod to the interpersonal is expected.

9 This musical-score transcription format is taken from the HIAT notation system (see Ehlich 1993) and has been used by several scholars of spoken interaction (e.g., Watts 2003, Bousfield 2008, O’Driscoll 2013). By representing time as spatial left-to-right movement across the page, it can indicate time-relationships between one person's contributions and another's fairly accurately without recourse to the proliferation of symbols found in other transcription systems.

10 This time the musical-score transcript has the innovation that each 'instrument' (i.e., participant) is given two 'staves' in each line, one for doings which can be heard (with transcribed words in bold typeface) and one below it for those which can be seen. Dots indicate continued activity. For the sake of ease of reading, conventional orthography and the same font have been used throughout, with the result that timing indicated by the left-to-right movement across the page is not a perfect representation. In line with the transcript used in the rest of the papers, Soto is ' $\mathrm{D}$ ', the judge is 'J.' 
$1 \mathrm{~J}$ : well how, h-how mu-ha-how much would you say you're jewellery's worth? Expressive use of hands

D: laughs

Holding arms together under chin

$2 \mathrm{~J}$ : its not a joke you know we are not in a- not in a club now Eh smiling Smile broadens

D: Laughter...... OK but it's you know arms together under chin stroking hair with both hands

$3 \mathrm{~J}$ : well you see we are not in a club be serious about it turns towards Soto and expressive, wide hand gesture, smile continues

D: kind of you knowI'm serious about it but it you Stroking hair and smiling.

$4 \mathrm{~J}: \quad$ I can see you're serious alright turns back to desk, smile disappears Looks ahead

it's alright how turns towards Soto

D: just made me laugh you just made me laugh I apologize

Smiling, stroking, one hand on chest..... Hand away from hair, held out (still smiling)

His interruption of her itemizing (stave 1), while relevant in its propositional content to the instrumental frame, is expressed in a conversational manner, spoken fast with several false starts, accompanied by expressive hand gestures and including "would you say". These features involve a clear move away from the impersonal, interrogation style to which Soto has so far been subjected. She is now being asked to perform an act of personal assessment, being personally engaged with. Thus a different, social-encounter frame which so far has only been hinted at by Soto is to some degree accommodated and she is being recognized for the first time as a full person rather than, as heretofore, an object-tobe-dealt-with.

Soto then effects further reframing in that direction by laughing (stave 1-2), which in a social-encounter frame can be interpreted as a metapragmatic comment on a 'too-personal' question. The judge's rebuff (stave 2) is a reminder of the court-hearing frame (presumably 'it' in 'it's not a joke' refers to the situation). However, his smile and the levity of his following comment about a club, preceded by "you know", indexes sociability and thus contributes to the socialencounter thread. He could have reminded her simply that this is not a social situation. But the club allusion brings up other connotations and associates Soto with these, thus commenting on her as an individual.

Soto indicates assent to the judge's observation but then attempts to verbally justify her metapragmatic stance (staves 2-3). This attempt is cut off by the judge, who repeats his club observation and enjoins her to "be serious". At the same time, however, he goes along with this change in tenor towards the socia- 
ble, smiling broadly, orienting himself towards Soto, gesturing with hands and adding a conversational "you see". In addition, this interruption is not an explicit warning to Soto to make her contribution relevant (that is, not a response to the start of a perceived invalid contribution), and thereby indexes a looser frame than that of the expected orderly sequence of question and answer in the ideal court frame. In this context, his reference to a club serves as a patronizing, amused kind of admonition and despite his exhortation for her to be serious, the effect is almost playful.

Soto's response (end of stave 3), instead of agreeing to abide by the judge's directive, takes issue with the implicature contained in it (that she is not being serious) and refutes it. Notice, then, that by this point the topic of talk is fully Soto's footing, not the value of her jewellery. She also (staves 3-4) attempts for a second time to explain her laughter as involuntary but again she does not succeed because again the judge interrupts, this time with an oblique comment on her claim to seriousness. In that this comment cuts off Soto's attempt to explain herself and is accompanied by a re-orientation to his desk and the disappearance of his smile, it brings us back to the impersonal court-hearing frame. But at the same time its off-the-cuff nature, its conclusion with the emphasizing "alright", plus the simple fact that its propositional content continues with the topic of her as a person rather than the matter institutionally at hand, continues to index a social-encounter frame. That this frame has by now been to some extent validated is shown by the fact that Soto feels able to repeat her explanation (mid stave 4) after it was not heard by the judge the first two times, serving both to re-affirm the social-encounter frame by referring to personal affect and also to follow this repositioning of herself as amusingly and childishly inappropriate by engaging in personal, face-salient dialogue. However, perhaps aware of the judge's possible irritation, she immediately proceeds to utter an apology, which the judge accepts and then utters a bald repetition of the question about jewellery.

Thus by this stage in the proceedings, both Soto and the judge, through a series of 'contextualization cues' (Gumperz 1982), have been shifting back and forth between two mutually exclusive styles of talk, the interrogatory and the conversational, and two opposed tenors of talk, the serious and the playful. Thereby, they have been intermingling two mutually exclusive frames, the court hearing and the social encounter. They have co-constructed this ambiguity, whereby a social situation has been indexed enough for Soto's footing to have shifted from a mere object-to-be-dealt-with to that of a recalcitrant junior, and that of the judge from a representative of the majesty of the law to that of an admonishing but forbearing senior. A relationship has been introduced, one which evokes uncle and niece or perhaps headmaster and amusingly naughty pupil. 
The subsequent exchanges similarly hint at a frame other than that of the court hearing. A precise value for Soto's jewellery is never established because she offers only an approximation ("a lot of money") and a comparison ("rick ross") and the judge's indication of not understanding this allusion to a famous rapper is an informal "huh?". When Soto struggles to find another way of indicating how much her jewellery is worth, the judge again switches the topic back to that of Soto's demeanour by asking her whether she is under the influence of drugs. The addition of "actually" to her negative answer allows a number of inferences. One is that she has interpreted the question as a matter of casual interest. Another is that, like the earlier laughter, it is a metapragmatic comment on the fact that the question has been asked at all (an inference supported by the exaggerated physical movements which immediately precede her response). Both these again index the social encounter frame. Yet another possible inference is that she is implying she is in the habit of taking drugs (just not - as it happens - in the last 24 hours). Whichever of these inferences has been drawn by the judge, the fact that he queries her use of this word further indexes a social frame and pushes the encounter further away from its designated purpose. He is not enquiring into the relevant facts but querying what she means.

As we have seen, the default footing for Soto for this frame is as a relatively profane person, one with no voluntary speaking rights who is only half 'there', with no face. However, the trajectory since the judge first took over the questioning of her has hinted at installing her as a full person. She never escapes from the restricted speaking rights but she has to some extent become a 'character', more than just a case-to-be-dealt-with. Their footings have shifted.

\section{The consequences of the dance}

Having traced this drift in footings and the insinuation of a different frame, I can now offer plausible accounts of the links in the chain of consequences.

\subsection{Judge: saying "bye-bye" with farewell hand gesture}

When the judge, having as far as he is concerned already terminated the encounter (see end section 5), notices Soto is still there, there is a need, unusual from his viewpoint, for some explicit dismissal to be issued. Considering the default non-person status of inmates in such encounters (as evidenced by the snippets of two other encounters on the video), a likely course of action would 
be to instruct the jailhouse staff to remove her. But all of the indexing of the social that has taken place induces him to dismiss her himself. A range of means are open to him. One might imagine various indirect directives such as "that will be all” or "you may leave", or even "thank you" or "goodbye". But the judge selects none of these options. Instead he opts for a phrase-and-gesture which in the context of a courtroom hearing is distinctly marked. We can of course never know with certainty why he made this choice. But we can note that it is perfectly consonant with the paternalistic footing which the trajectory of the encounter has insinuated for him and the child footing which it has insinuated for her.

\subsection{Soto: saying "adios"}

Along the same trajectory, and encouraged by the judge's markedly phatic phrase of farewell, which makes her 'new' child footing overt, Soto utters a phrase of farewell perfectly consonant with it. She received an informal farewell, so she gives a 'cutesy' farewell back, the kind she might easily give to older relatives.

\subsection{Judge: doubling the bail amount}

Right up to this point, however irritated he might have been by her behaviour during the encounter, the judge is prepared to see matters as settled and the encounter finished. This single, innocuous word causes him to get her back in front of the VL, double her bail and then utter another farewell which appears to be sarcastic. Why?

One reason is that she said anything at all when taking her leave. The previous inmate did not. His farewell phrase and gesture was presumably an ironic means of dismissal. By giving farewell back, Soto has called his bluff. Moreover, she has thereby positioned herself as a full person entitled to ritual deference, contra the default footings for these encounters.

Nevertheless, while we may not discount the strength of authority's desire to have the last word, that 'adios' was surely just a peccadillo. There must be additional motivations for him to act. These presumably involve the precise form of her farewell, which clearly has an impact on the judge because he indexes it in his $2^{\text {nd }}$ dismissal of her. One obvious feature is that it projects entirely new footings for both the judge and Soto as fellow Latinos (for a discussion of this aspect, see Christie, this volume). Given that none of the other ratified participants have Latino voices, a special affinity with each other is 
thereby projected. This positive facework could be experienced by the judge as severely threatening to his negative face (see O’Driscoll 2007). Here, however, I want to suggest a threat to another aspect of his face.

Notwithstanding frame expectations, it is not always the judge who has effective topic and frame control. It is Soto who, by laughing at the question put to her about the value of her jewellery, most forcefully indexes the social encounter frame which has up to that point only been hinted at. In response, the judge does not reassert the court hearing frame but rather introduces the topic of her demeanour. In particular, it is more obviously Soto, through the performative nature of her apology for laughing ("I apologise"), who drags the encounter back to the default frame - but only after insisting on getting her previously ignored self-justifying personal point across. She retains the social encounter frame at this point; then she flicks the court-hearing-frame switch. Notice also that the judge never succeeds in establishing the monetary value of her jewellery despite repeated attempts. When she struggles in her attempt to give such a value, the judge gets sidetracked onto her demeanour again, first by his drugs query, then by her 'actually'. Then the lawyer interrupts and he gives up this line of enquiry.

Given then, that he is only very imperfectly performing the control vested in him, his face may be vulnerable. In this light, the gasp of amusement from a female member of the legal staff, clearly audible on the recording, which immediately follows Soto's 'adios' is crucial. It is perhaps this move which turns a vulnerable face into a threatened one; not only does he consider he has been 'cheeked' - now he is seen to have been cheeked. So he cannot just let it pass.

It is perfectly possible that there is also a more impersonal rationale for the judge's behaviour at this point. This analysis has examined the behaviour of both Soto and the judge during the encounter. But it is the prerogative of the powerful to examine only the behaviour of the less powerful. Notwithstanding his part in encouraging it, the judge may have assessed Soto's behaviour and demeanour throughout as inappropriate, that her apparent enjoyment (all that laughter and smiling) demonstrates a lack of contrition, that her apparent ability to insert herself as a person into proceedings demonstrates a lack of proper humility. She just wasn't chastened enough. From this viewpoint, it is not the judge's face that is at stake but the dignity of the law. And from this viewpoint, that insolent 'adios' was just the straw that broke the camel's back.

However, some sort of appeal to face must be made in order to account for the manner in which he doubles the bail. He calls her back with a smile, but this disappears when she arrives in view and does not reappear as he gets the necessary document back from the legal staff, announces that bail will be $\$ 10,000$ and amends the document accordingly. No hint of explanation is prof- 
fered and there is only the briefest of glances in her direction. It is an overt demonstration of absolute, almost whimsical, power which puts Soto firmly back in her non-person place.

\subsection{Soto: 'fuck you' with finger gesture}

Soto has to this point shown no interest whatsoever in the amount of bail to be set. If $\$ 5,000$ was no problem, why does $\$ 10,000$ appear to be such a very big deal, big enough to provoke a move which a second's consideration would have told her will be disastrous for her? The answer must be that this move is not a reaction to instrumental considerations. Very obviously, she is not acting rationally, but in the moment.

Along this line of thinking, there are two possibilities, not entirely mutually exclusive. The first concerns the social aspects of footing. The indices of a social encounter during the interaction have encouraged her to feel she is a 'full' person who has established some sort of relationship with the judge and this is why, it has been suggested, she felt it OK to utter (or at least to get away with uttering) a cutesy farewell to the judge. His extreme reaction now makes her feel tricked. She may even feel hurt by his sarcastic 'adios' - note that she displays a shocked face not only at the announcement of the new bail amount but also again at this utterance. And if her 'adios' did indeed include an appeal to shared ethnicity, its sarcastic return (with a markedly different pronunciation) has thrown this appeal back in her face.

I am suggesting, then, an affective provocation. But assuming she is a person of minimal self-control, this alone cannot satisfactorily explain her reaction. So there is another possible explanation which involves us returning to participation framework and considering the possibility of bystanders to this encounter. If there are bystanders at Soto's end of the VL, we may guess that she has a peculiarly strong awareness of them - she is in their immediate presence, and they in hers, while she is in only the mediated presence of even her fellow ratified participants (and they in hers). We know for sure there is one inmate in this role (standing in the up-next position) and we can presume there is at least one jailhouse official there too (the one who appears to halt Soto at the start of the encounter). Is there anyone else?

After the judge has called her back, and she stands again in the encounter position waiting for him to speak, she twice turns laughingly to her right, the direction from which she returned. When the judge announces $\$ 10,000$, there is an aspect of melodrama in her shocked face, whose sincerity is somewhat belied by a continued smile. During this period, lots of background comment and laughter can be heard on the recording, which seems to be coming from the 
jailhouse end of the VL. The conclusion to be drawn from these observations is that there are several inmate overhearers who can see her movements and hear her words clearly. It is not fanciful to suppose that her subsequent outburst is very much for their benefit - more precisely, for the benefit of her face with them. In support of this supposition, notice that her action takes place right at the edge of the screen, after she has vacated the encounter-position. In view of the fact that at the commencement of the encounter she was not treated as a ratified participant until she was called fully forward into this position, she may consider herself to have been removed from the encounter once she has vacated it. In other words, it is quite possible she is not aware that her outburst is visible and audible to the judge, that for her what is going on at this point is unfocused interaction, with her taking account of the fellow inmates in whose presence she resides, unaware that she also resides in the presence of a very different group of people at the other end of the VL.

\subsection{Judge: sentencing Soto to 30 days in jail}

We have now travelled right back up the chain of causality. This final act is relatively self-evident. Soto's bald, taboo malediction, reinforced with the taboo gesture, constitutes a severe attack on the judge's face and is interpreted by him as an attack on the dignity of the court. Whether there is sufficient legal warrant for his decision is not, being legal, a matter for this article.

\section{A conclusion of sorts}

This article has shown that the application of Goffmanian concepts to the analysis of a piece of interaction affords genuine insights into participants' behaviour. It can, moreover, even offer plausible explanations for this behaviour with relatively little recourse to speculations about mental and emotional states. This is possible because, while Goffman places the individual at the centre of attention, his concepts are designed to illuminate situational realities. His individual is the interacting, performed individual, who is being witnessed and can witness s/he is being witnessed, not a manifestation of any putative psychological state. Any approach to understanding the feelings or thoughts of the inner person comes from this external direction, from what is visible and/ or audible. His notions of face and footing, for example, both describe the individual, and both hint at an internal aspect (of affect and/or cognition), but 
both are determined at any one time by what can be witnessed. The next four paragraphs offer some thoughts on particular concepts.

1. The analysis here, like that of Grainger (this volume), exemplifies how concerns for face can protrude into encounters in which personal relationships are not canonically relevant. These concerns (contra the conceptualization of face in Brown and Levinson 1987) seem to operate alongside, and to some degree independently of, rational ones (see O'Driscoll 2017: 107-111 for a further example). Indeed, the final spate of interaction in the Soto-judge encounter sees them operate in apparent opposition to these. When Soto is called back again, her demeanour in front of the VL is very different from what it has been. From a rational viewpoint, one might expect an abject apology along with the explanation that her outburst was not intended to be accessible to the court. But instead, she adopts an overtly confrontational stance, squares up to the judge with a serious facial expression and folded arms, issues the challenging "What's up?" and then, when questioned by the judge whether he really heard "fuck you", freely admits to her delict and adds a comment ("I'm not going to deny it") which implies she has no intention of 'taking it back' - or even apologizing for it. She does this because she now has a face to maintain with her fellow inmates (see 7.4 above) which has become more important to her than any substantive outcome.

2. In this article, I have attempted a development of the notion of participation framework. In that it pertains to a frozen moment, this notion is a component of footing. But I have proposed we also think in terms of participation framework patterns for whole encounters, a notion that relates to that of frame. After all, one crucial aspect of expectations about participants' behaviour (itself a crucial aspect of frame) is who among them is to do the talking, who they talk directly to, whether and to what extent others get a chance to speak and so on. In the analysis above, I implied a distinction between canonical participation framework patterns (what one expects in the abstract given a certain broad category of activity type), default patterns (what one gets given local contingencies) and actual patterns (what can be observed of a particular encounter). These distinctions seemed useful in the Soto case. Whether they can prove more widely useful remains to be seen. Participation framework patterns, with consideration of these different degrees of specificity, offer one way of exploring how footings at the momentary (utterance or move) level, and footings at the encounter (frame or activity type) level, impact on each other. They could perhaps be used alongside the notion of discourse types (acts or sequences of acts which can be related to the activity type) as outlined by Sarangi (2000) and utilized by, for example, Halvorsen and Sarangi (2015).

3. As we have seen, the marginalization of Soto during this encounter suggests an apparent boundary problem for the categories of participation frame- 
work. There is one other feature of the interaction here which does likewise and in addition raises a problem for the notion of encounter as a single, bounded event. Consider the jailhouse staff. In the normal run, they do not seem to be ratified as participants in judge-inmate encounters. But at one point, the judge addresses them directly ("bring her back"). They appear then to be nevertheless 'on call' for inclusion in the ratified circle. Note also that they have a role to play in ensuring a smooth transition from one such encounter to the next, so that they are, we must say, ratified with regard to the series of encounters. Phenomena of this kind do not seriously call into question the two notions (and Goffman himself seems to revel in examples of their fuzziness), but they serve as a caveat to their over-reification. Indeed, as has been implied in the analysis here, Goffman's categories are better seen not as pigeon-holes into which participant roles must always be stuffed, but rather as reference points for the precise mapping of roles at precise junctures.

4. The utility of the category of a move (as an act realized through speech or something else or both together) has not been demonstrated. Having introduced it, this article has not used it much. The problem is that different significant behavioural features can take place all at once but span different lengths of time. To make the concept systematically operational, therefore, one would have to atomize it and allow each description of a move to refer to only one of propositional content of speech, paralinguistic speech features, gaze, facial expression, bodily orientation or gesture. This would be unsatisfactory because "visible human conduct is integral with the use of linguistic forms. There is only one system of embodied communicative behavior, not a system of visible conduct distinct from a system of linguistic behavior" (Arundale 2013: 13). Nevertheless, the value of taking all the above features into potential account and, in a Goffmanian spirit, of not assuming pre-eminence for the first of them is, on the evidence of the analysis here, transparent.

Finally, a comment on the use of a video link for this kind of event: As Licoppe and Veyrier (2017: 161) observe, this practice "raises new issues regarding visibility and participatory statuses in the courtroom". The emphasis in this work and others on this topic (e.g., Licoppe 2015) is on the effect of "camera actions' on the possible interpretation of what participants say and do. Here, such an effect does not apply, as the split screen shots are static throughout. However, it has been suggested that the video link arrangement in this case was a factor in participants' behaviour itself, the most glaring example being Soto's performance of angry defiance at the end of the encounter, her bystanders occupying a larger part of her consciousness than her fellow ratified participants. That this is so follows from Goffman's understanding of interaction itself, which involves all those co-present mutually monitoring each other. In unmedi- 
ated face-to-face focused interaction, all those involved can place everyone else present in a 3D 'frame' as wide as the field of vision afforded by their eyesight. And being relatively physically close to each other, they can hear more-or-less what everyone else can hear. If there are bystanders, all participants will be aware of them to a more-or-less equal extent (and the bystanders themselves will have a view of all the participants). They inhabit the same world of the senses. For those at opposite ends of a VL, on the other hand, the possibilities for mutual monitoring are quite severely limited. Depth of vision is flattened and of course the field of vision is only as wide as the screen, to such an extent that in a multi-person encounter, a participant at one end of the VL may not be able to see all the participants at the other end at the same time. And opposite ends of the screen may be attended by different groups of bystanders, participants at one end being perhaps totally unaware, and certainly not keenly aware, of bystanders at the other.

These limitations cannot but affect behaviour. The presence of mediated participants is inevitably felt less keenly than in a face-to-face encounter. During the encounter we have been examining, Soto, especially at first, bends forward to speak, as if some special effort were required to ensure that her words find their target, and indicating an awareness that she is addressing someone whose range of hearing and vision is limited. It is no wonder that her behaviour is influenced inordinately by the presence of the bystanders at her end. It is reasonable to suppose that the behaviour of those at the courtroom end is likewise influenced. All the features contributing to the de-ratification of Soto (section 5 above) must have been encouraged by the same sensory limitations. Finally, we can see that these dislocated conditions may have facilitated the shifts and drift in footing and frame which made the trajectory of the encounter so unfortunate. Would the judge have allowed himself that "bye-bye" if the encounter had been unmediated. Would Soto have responded "adios”? Perhaps not.

\section{References}

Arundale, Robert B. 2013. Conceptualizing 'interaction' in interpersonal pragmatics: Implications for understanding and research. Journal of Pragmatics 58. 12-26. Bousfield, Derek. 2008. Impoliteness in Interaction. Amsterdam: John Benjamins. Brown, Penelope \& Stephen C. Levinson. 1987. Politeness: Some Universals in Language Usage. Cambridge: Cambridge University Press.

Christie, Christine. (this issue). The indexical scope of adios: a relevance theoretic analysis of discursive constructions of gender and institutions and their impact on utterance interpretation. 
Ehlich, Konrad. 1993. HIAT: a transcription system for discourse data. In Jane A. Edwards \& Martin D. Lampert (eds.). Talking Data, 123-148. Hillsdale, NJ: Lawrence Erlbaum.

Goffman, Erving. 1959. The Presentation of Self in Everyday Life. Harmondsworth: Penguin.

Goffman, Erving. 1961. Asylums: Essays on the Social Situation of Mental Patients and Other Inmates. Harmondsworth: Penguin.

Goffman, Erving. 1963a. Stigma: Notes on the Management of Spoiled Identity. Harmondsworth: Penguin.

Goffman, Erving. 1963b. Behavior in Public Places: Notes on the Social Organization of Gatherings. New York: The Free Press.

Goffman, Erving. 1964. The Neglected Situation. American Anthropologist 66(6). 133-136.

Goffman, Erving. 1967. Interaction Ritual: Essays on Face-to-Face Behavior. Harmondsworth: Penguin.

Goffman, Erving. 1971. Relations in Public: Microstudies of the Public Order. Harmondsworth: Penguin.

Goffman, Erving. 1974. Frame Analysis: An Essay on the Organization of Experience. Peregrine Books (Penguin).

Goffman, Erving. 1981. Forms of Talk. Philadelphia: University of Pennsylvania Press.

Goodwin, Charles \& Alessandro Duranti. 1992. Rethinking Context: An introduction. In Duranti \& Goodwin (eds.). Rethinking Context: Language as an interactive phenomenon 1-42. Cambridge: Cambridge University Press.

Grainger, Karen (this volume). "We're not in a club now": a neo-Brown and Levinson approach to analyzing courtroom data.

Grice, H. Paul. 1975. Logic and conversation. In: Peter Cole \& Jerry Morgan (eds.). Speech Acts [Syntax and Semantics 3], 41-58. New York: Academic Press.

Gumperz, John. 1982. Discourse Strategies. Cambridge: Cambridge University Press.

Halvorsen, Kristin \& Srikant Sarangi 2015. Team decision-making in workplace meetings: The interplay of activity roles and discourse roles. Journal of Pragmatics 76. 1-14.

Irvine, Judith T. 1996. Shadow conversations: the indeterminacy of participant roles. In Michael Silverstein \& Greg Urban (eds.). Natural Histories of Discourse, 131-159. University of Chicago Press.

Kendon, Adam. 1990. Conducting interaction: Patterns of behaviour in focused encounters. Cambridge: Cambridge University Press.

Levinson, Stephen C. 1979. Activity types and language. Linguistics 17(5-6). 365-399. Reprinted in Paul Drew \& John Heritage (eds.) 1992. Talk at Work: Interaction in institutional settings. 66-100. Cambridge: Cambridge University Press.

Levinson, Stephen C. 1988. Putting Linguistics on a proper footing. In Paul Drew \& Anthony Wooton (eds.) Erving Goffman: exploring the interaction order 161-227. Cambridge: Polity Press.

Licoppe, Christian. 2015. Video communication and 'camera actions': The production of wide video shots in courtrooms with remote defendants. Journal of Pragmatics 76. 117-134.

Licoppe, Christian \& Clair-Antoine Veyrier. 2017. How to show the interpreter on screen? The normative organization of visual ecologies in multilingual courtrooms with video links. Journal of Pragmatics 107. 147-164.

O’Driscoll, Jim. 2007. Brown \& Levinson's face: how it can - and can't - help us to understand interaction across cultures. Intercultural Pragmatics 4(4). 463-492.

O’Driscoll, Jim. 2009. Erving Goffman. In Sigurd D’hondt, Jan-Ola Östman \& Jef Verschueren. (eds.). The Pragmatics of Interaction. (Handbook of Pragmatics Highlights. vol. 4), 79-95. Amsterdam: John Benjamin. 
O'Driscoll, Jim. 2013. The role of language in interpersonal pragmatics. Journal of Pragmatics 58. 170-181.

O’Driscoll, Jim. 2017. Face \& (im)politeness. In Jonathan Culpeper, Michael Haugh \& Daniel Kádár (eds.). The Palgrave Handbook of Linguistic (Im)politeness 89-118. London: Palgrave MacMillan.

Sarangi, Srikant. 2000. Activity types, discourse types and interactional hybridity. In Srikant Sarangi \& Malcolm Coulthard (eds.). Discourse and Social Life 1-27. London: Longman.

Sarangi, Srikant \& Stefan Slembrouck. 1996. Language, Bureaucracy and Social Control. London: Longman.

Schank, Roger \& Robert P. Abelson. 1977. Scripts, plans, goals, and understanding. An enquiry into human knowledge structures. Hillsdale, NJ: Lawrence Erlbaum.

Schegloff, Emmanuel. 1968. Sequencing in conversational openings. American Anthropologist 70. 1075-1095.

Schegloff, Emmanuel \& Harvey Sacks. 1973. Opening up closings. Semiotica 8(4). 289-327.

Tannen, Deborah. 1993. What's in a frame? Surface evidence for underlying expectations. In Deborah Tannen. (ed.). Framing in Discourse 14-56. Oxford: Oxford University Press.

Thomas, Jenny. 1986. The Dynamics of Discourse: A Pragmatic Analysis of Confrontational Interaction. Unpublished doctoral thesis, Lancaster University, UK.

Watts, Richard J. 1989. Relevance and relational work: Linguistic politeness as politic behavior. Multilingua 8(2-3). 131-166.

Watts, Richard J. 1992. Linguistic politeness and politic verbal behaviour: Reconsidering claims for universality. In Richard Watts, Sachiko Ide \& Konrad Ehlich (eds.). Politeness in Language: Studies in its History, Theory and Practice, 43-69. Berlin and New York: Mouton de Gruyter.

Watts, Richard J. 2003. Politeness. Cambridge: Cambridge University Press.

\section{Bionote}

\section{Jim O’Driscoll}

Jim O'Driscoll is a member of the Language-in-Conflict team at the University of Huddersfield. His research interests straddle several aspects of language-in-situated-use. His articles have appeared in Journal of Pragmatics, Intercultural Pragmatics, Journal of Politeness Research, Multilingua, Pragmatics and Society, Journal of Multilingual and Multicultural Development and various edited collections, among which is the article on Erving Goffman which appears in the Handbook of Pragmatics Highlights 4. 